\title{
Increased Risk of Childhood Acute Lymphoblastic Leukemia (ALL) by Prenatal and Postnatal Exposure to High Voltage Power Lines : A Case Control Study in Isfahan, Iran
}

\author{
Maral Mazloomi Tabrizi, Sepideh Arbabi Bidgoli*
}

\begin{abstract}
Childhood acute lymphoblastic leukemia (ALL) is one of the most common hematologic malignancies, accounting for one fourth of all childhood cancer cases. Exposure to environmental factors around the time of conception or pregnancy can increase the risk of ALL in the offspring. This study aimed to evaluted the role of prenatal and postnatal exposure to high voltage power lines on the incidence of childhood ALL.This cross-sectional case control study was carried out on 22 cases and 100 controls who were born and lived in low socioeconomic families in Isfahan and hospitalized for therapeutic purposes in different hospitals from 2013-2014. With regard to the underlying risk factors, familial history and parental factors were noted but in this age, socioeonomic and zonal matched case control study, prenatal and childhood exposure to high voltage power lines was considered as the most important environmental risk factors of $A L L(p=0.006, O R=3.651, C I 95 \%, 1.692-7.878)$. As the population was of low socioeconomic background, use of mobiles, computers and microwave was negligible. Moreover prenatal and postnatal exposure to indoor electrically charged objects was not determined to be a significant environmental factor. Thus, pre and post natal exposure to high voltage power lines and living in pollutant regions as well as familial influence could be described as risk factors of ALL for the first time in a low socioeconomic status Iranian population
\end{abstract}

Keywords: Leukemia - acute lymphoblastic leukemia - childhood cancer - electromagnetic field - Isfahan - Iran

Asian Pac J Cancer Prev, 16 (6), 2347-2350

\section{Introduction}

Cancer has become as the second most common cause of death in developing countries (Roshandel et al., 2014) and childhood cancer is the second most common cause of death in children in developing countries (Lupo et al., 2014). Childhood cancer incidence has been increased by approximately $0.5 \%$ per year in united states (Hauri D, Cohort, and (SPOG) 2013) and childhood Acute Lymphoblastic Leukemia (ALL) has been considered as the most common hematologic and childhood malignancy which accounts for one fourth of all childhood cancer cases (Reisi et al., 2009).

Many epidemiologic studies have evaluated a wide range of maternal (Milne et al., 2015) and paternal nutritional factors as the major ethiologic factors of ALL (Bailey et al., 2014) but based on the largest number of childhood leukemia case study to date, risk of ALL could be reduced by maternal prenatal use of vitamins and folic acid. Moreover the association of ALL with parental education as a surrogate for lifestyle and sociodemographic characteristics has been recently suggested too (Metayer et al., 2014). Other than nutritional factors and the protective role of parental supplementation in risk reduction of ALL (Lupo et al., 2014), there are controversial evidences regarding the role of paternal residential and occupational exposures like paint (Bailey, 2014), PAHs (Deziel et al., 2014), pesticide exposures (Bailey, 2014), exposure to diagnostic radiological procedures (Bailey and Consortium, 2010) around the time of conception or pregnancy in increased risk of ALL in the offspring.

For many years, residential and occupational exposures to Electromagnetic fields (EMF) has been considered as possible human carcinogen, based on some epidemiological studies. These studies suggest the role of this exposure and increased risk of childhood leukemia, adult leukemia and adult brain tumors following chronic exposure to MF (D'Angelo et al., 2015). Because of limited evicdences on the ethiology of ALL in Iran, we aimed in present study to analysis a wide range of utero exposure, maternal, paternal and childhood exposures as well as other possible risk factors of ALL by a general focus on exposing to Electromagnetic fields (EMF) in Isfahan as one the most polluted cities of Iran in a case control setting. 


\section{Materials and Methods}

\section{Population study}

A case-control cross sectional study was carried out among 22 newly diagnosed ALL and 100 normal children who were all $<12$ years, born and grown up in Isfahan. Leukemia were identified from both self-reports registration and ALL was confirmed by evaluating their pathological reports. Exclusion criteria for cases and controls were lack of access to the parents, birth and living out of Isfahan and having moderate and higher socioeconomic state. The control group was matched with cases for age \pm 5 years who born and lived in the same region.

Electromagnetic fields (EMF): Living near high voltage power lines, using mobiles, computers, microwave and all indoor electrically charged objects were considered for inclusion as a potentially important environmental factor in the present study (Sohrabi, 2010).

\section{Identification of environmental resources}

Exact living and working addresses of cases and controls were recorded and matched with the map of factories generating PAHs, dioxins, pesticides and other pollutants. A complete list of factories that release toxicants with hormone-like effects was provided before starting the study.

The families who lived within $4 \mathrm{~km}$ from the pollutant factories were considered for assessment as high risk families. Occupational exposures to chemicals, radiation, using plastic water and food containers through validated questionnaire.

\section{Identification of background variables}

Demographical variables were obtained from specific questionnaire items: Delivery related factors including place of birth, paternal and maternal ages at delivery, BMI, education, job, socioeconomic states, physical activity, Personal history of any disorders, birth weight at delivery; familial history of leukemia, mother's irregular menstruation, marriage related factors including marital status of parents, age at marriage.

\section{Maternal related factors}

Information on hormone use was obtained from specific questionnaire items. They covered questions on ever and current use of oral contraceptive pills (OCPs), the brand names, age at start and total duration of the use. Other methods of contraception were recorded including use of intrauterine device, tubectomy and use of progestins. Pregnancy related factors including number of full-term pregnancies, age and maximum weight gain at each pregnancy, months of breast feeding at each delivery, history of abortion induction were recorded. History of infertility covered questions on years of infertility, i.e., more than 2 years without birth controlling methods, use of ovulation stimulating drugs, hormone therapy or history of in vitro fertilization. Patients were asked their gynecological disorders including ovarian cysts, uterine firoadenoma, irregular menstruation, hyrsutism and other disorders.

\section{Statistical methods}

Values were expressed as percent per population or as the mean standard deviation. To assess associations between parametric variables Student $t$-test and to evaluate nonparametric data, the chi square test was used. Relative risks and odds ratios were calculated by the Cochran-Mantel-Haenszel statistics using SPSS 16 and the odds ratios were reported for this case control retrospective study. When the odds ratio in cases was $>1$, if the probability values was $<0.05$ and when the $5 \%$ confidence interval of the true odds ratio was greater than 1 , then we interpreted it as significant risk factor. When the odds ratio in controls was $<1$, if the probability values was $<0.05$ and when the $5 \%$ confidence interval of the true odds ratio was less than 1 , then we interpreted it as protective factor.

\section{Results}

Electromagnetic fields (EMF): In this age, socioeonomic and zonal matched case control study prenatal and childhood exposure to high voltage power lines was considered as the most important environmental

Table 1. Comparison of Prenatal and Childhood Environmental Exposures between ALL Cases and Controls

\begin{tabular}{|c|c|c|c|c|c|c|}
\hline \multirow[t]{2}{*}{ Characteristics } & \multirow{2}{*}{$\begin{array}{l}\text { Case } \\
(\mathrm{n}=22)\end{array}$} & \multirow{2}{*}{$\begin{array}{l}\text { Control } \\
(\mathrm{n}=100)\end{array}$} & \multirow[t]{2}{*}{ P-Value } & \multirow[t]{2}{*}{ OR } & \multicolumn{2}{|c|}{ CI $95 \%$} \\
\hline & & & & & Lower & Upper \\
\hline \multicolumn{7}{|c|}{ Prenatal exposure to high voltage power lines } \\
\hline Yes & $4(18.18 \%)$ & $3(3 \%)$ & 0.006 & 3.651 & 1.692 & 7.878 \\
\hline No & $18(81.81 \%)$ & $97(97 \%)$ & & & & \\
\hline \multicolumn{7}{|c|}{ Neonatal and childhood exposure to high voltage power lines ( $>4 \mathrm{yrs})$} \\
\hline Yes & $4(18.18 \%)$ & $3(3 \%)$ & 0.006 & 3.651 & 1.692 & 7.878 \\
\hline No & $18(81.81 \%)$ & $97(97 \%)$ & & & & \\
\hline \multicolumn{7}{|c|}{ Keep food and water in plastic containers } \\
\hline Yes & $13(59.09 \%)$ & $22(22 \%)$ & $0.001>$ & 3.590 & 1.689 & 7.631 \\
\hline No & $9(40.90 \%)$ & $78(78 \%)$ & & & & \\
\hline \multicolumn{7}{|c|}{ Living near polluting factories $(<4 \mathrm{~km})$} \\
\hline Yes & $5(22.72 \%)$ & $5(5 \%)$ & 0.006 & 3.265 & 1.529 & 6.971 \\
\hline No & $17(77.27 \%)$ & $95(95 \%)$ & & & & \\
\hline \multicolumn{7}{|c|}{ Sunlight exposure $(<2 \mathrm{hrs})$} \\
\hline Yes & $16(72.72 \%)$ & $47(47 \%)$ & 0.029 & 2.497 & 1.048 & 5.952 \\
\hline No & $6(27.27 \%)$ & $53(53 \%)$ & & & & \\
\hline
\end{tabular}


Table 2. Comparison of Parental/Familial risk factors between ALL Cases and Controls

\begin{tabular}{|c|c|c|c|c|c|c|}
\hline \multirow[t]{2}{*}{ Characteristics } & \multirow{2}{*}{$\begin{array}{c}\text { Case } \\
(n=22)\end{array}$} & \multirow{2}{*}{$\begin{array}{l}\text { Control } \\
(\mathrm{n}=100)\end{array}$} & \multirow[t]{2}{*}{ P-Value } & \multirow[t]{2}{*}{ OR } & \multicolumn{2}{|c|}{ CI $95 \%$} \\
\hline & & & & & Lower & Upper \\
\hline \multicolumn{7}{|c|}{ Familial history of leukemia } \\
\hline Yes & $8(36.36 \%)$ & $0(0 \%)$ & $<0.001$ & $8.143^{*}$ & 4.986 & 13.30 \\
\hline No & $14(63.63 \%)$ & $100(100 \%)$ & & & & \\
\hline \multicolumn{7}{|c|}{ Parental history of occupational exposure } \\
\hline Yes & $10(45.45 \%)$ & $2(2 \%)$ & $<0.001$ & $7.639 *$ & 4.230 & 13.79 \\
\hline No & $12(54.54 \%)$ & $99(99 \%)$ & & & & \\
\hline \multicolumn{7}{|c|}{ Exposure to X-rays around the time of conception or pregnancy } \\
\hline Yes & $3(13.63 \%)$ & $40(40 \%)$ & 0.019 & $4.222 *$ & 1.172 & 15.21 \\
\hline No & $19(86.36 \%)$ & $60(60 \%)$ & & & & \\
\hline \multicolumn{7}{|c|}{ Maternal severe stress around the time of conception or pregnancy } \\
\hline Yes & $6(27.27 \%)$ & $6(6 \%)$ & 0.002 & $3.438^{*}$ & 1.665 & 7.096 \\
\hline No & $16(72.72 \%)$ & $94(94 \%)$ & & & & \\
\hline \multicolumn{7}{|c|}{ Parental consanguinity } \\
\hline Yes & $8(36.3 \%)$ & $14(14 \%)$ & 0.014 & $2.597 *$ & 1.244 & 5.42 \\
\hline No & $14(63.63 \%)$ & $86(86 \%)$ & & & & \\
\hline \multicolumn{7}{|c|}{ Menstrual irregularities in mothers before conception } \\
\hline Yes & $11(50 \%)$ & $26(26 \%)$ & 0.027 & $2.297 *$ & 1.095 & 4.821 \\
\hline No & $11(50 \%)$ & $74(74 \%)$ & & & & \\
\hline
\end{tabular}

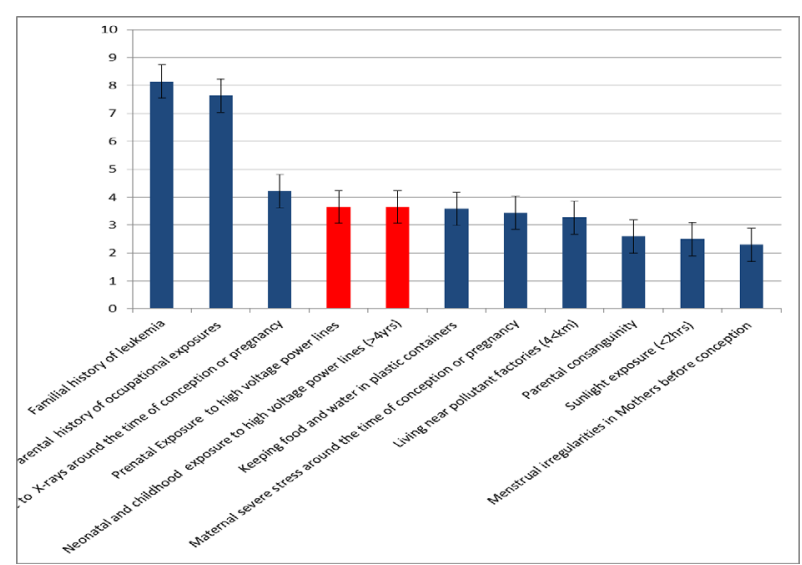

Figure 1. Ranking of ALL Risk factors According to the Odds Ratios

risk factors of $\mathrm{ALL}(\mathrm{p}=0.006, \mathrm{OR}=3.651,95 \% \mathrm{CI} 1.692-$ 7.878). In fact $18.8 \%$ of ALL children had continuous exposure to high voltage power lines from prenatal time to 4th age. As the population study was from low socioeconomic state, using mobiles,computers, microwave was negligible. Moreover prenatal and postnatal exposure to all indoor electrically charged objects were not detected as significant environmental factors in present study.

Identification of environmental resources : Consumption of food and water from plastic containers in these children was considered as the second important risk factor $(\mathrm{p}<0.001, \mathrm{OR}=3.651,95 \% \mathrm{CI} 1.689-7.631)$. Living near pollutant factories $(4<\mathrm{km})$ was considered as the next important risk factor of ALL $(\mathrm{p}=0.006, \mathrm{OR}=3.265$, $95 \% \mathrm{CI}$ ). The last factor out of 50 evaluated variables was sunlight exposure $(\mathrm{p}=0.029, \mathrm{OR}=1.048,95 \% \mathrm{CI}=1.048$ 5.952) in this case control study (Table 1).

Identification of Familial background factors : Out of 50 evaluated background factors, familial history of leukemia was considered as the the most imprtant risk factor of ALL in this young ( $<12$ years) population $(\mathrm{p}<0.001, \mathrm{OR}=8.143,95 \% \mathrm{CI}$ 4.986-13.3). Parental history of occupational expoures was also considered as the second important risk factor of $\operatorname{ALL}(\mathrm{P}<0.001, \mathrm{OR}=$
7.639, 95\% CI 4.23-13.794).Other important background factors are ranked in table 2 . This study phase showed the role of parental X-ray exposure before of at conception time, maternal severe stress in pregnancy, parental consanguinity and menstrual irregularities in the mothers of ALL children when compared with normal children.

\section{Discussion}

Recent evidences according to epidemiological studies, support a clear association between socioeconomic status and increased risk of childhood cancers (Hashemizadeh et al., 2013), (Njoku et al., 2013) especially in ALL (Metayer et al., 2014). This study tried to find the possible risk factors of ALL in low socioeconomic population in industrial regions of Isfahan by focusing on the role of electromagnetic fields for the first time in this group of patients in Iran.

Several local epidemiological studies have been conducted in different provinces of Iran including Mazandaran (Tahmasby et al., 2013), Golestan (Rajabli et al., 2013) and Khorasan Razavi (Hashemizadeh et al., 2013)on the prevalence of Leukemia and its possible risk factors.Although the obtained findings in the last study showed clear differences in the incidence rates of Leukemia based on age, gender, residence, and type of malignancy, ALL was considered as the most prevalent type of leukemia. For this reasons we focused on the paternal, maternal background factors, prenatal and postnatal environmental exposures in Isfahan as a city with higher levels of air pollution (Rashidi et al., 2013) (Janghorbani et al., 2013) and soil pollution (Mohajer et al., 2013).We considered here 11 most significant causes and considered the specific role of prenatal and postnatal(>4yrs) exposure to high voltage power lines as the most important environmental risk factors of $\operatorname{ALL}(\mathrm{p}=0.006, \mathrm{OR}=3.651,95 \% \mathrm{CI} 1.692-7.878)$.For some childhood cancers, such as acute lymphoblastic leukemia (ALL), there is evidence of an embryonic cell of origin (Marshall et al., 2014) therefore we assessed the prenatal 
factors in this study at the first part of assessments and found the dramatic carcinogenic effects of living near high voltage power lines in prenatal and postnatal periods.

We observed in present setting that the incidence of leukemia in first degree family of patients may increase the ALL risk more than 8 times $(\mathrm{p}<0.001, \mathrm{OR}=8.143,95 \% \mathrm{CI}$ 4.986-13.3) and considered the other factors (Figure 1).This results confirm the role of family cancer history which was previously considered in a population-based case-control study in chronic lymphocytic leukemia cases. This study in Baltimore suggested a genetic component for leukemia occurrence in several case families, although the majority of cases of leukemia appeared to be sporadic (Zierhut et al., 2012).

In present work we considered the etiology of ALL for the first time in Iranian population but despite the significant role of family history, the rest of children $14(63.63 \%)$ didn't have any history of malignancy in their first degrees and urge the scientists to evaluate the role of environmental factors.

The second ranked important background factor was parental occupational exposures. Out of 22 patients, 10 children $(45.45 \%$ vs $2 \%)$ showed paternal exposure to chemicals (diesel oil, gasoline, paints, insecticides, pesticides, herbicides, and chemical fertilizers) before and at the conception time or paternal working experiences in agriculture and forestry before pregnancy, leather processing, decoration, and vehicle repair $(\mathrm{P}<0.001$, OR $=7.639,95 \%$ CI $4.23-13.794)$ in accordance with results of parallel work in China (Shi et al., 2013).

In conclusion, his work has defined the forces of environmental exposures especially continuous pre and post natal exposure to high voltage power lines and living in pollutant regions through the parents or children as well as the role of previously described risk factors of ALL for the first time in low socioeconomic Iranian population. We confirmed here a new risk factor for ALL and suggest the hypothesis on embryonic origin of many other cancers which should be assessed in next studies in larger case control studies.

\section{Acknowledgements}

Authors are thankful to Ms. Mina Montazeri who has helped us to select and interview the patients who were hospitalized in Isfahan during this study from 2013-2014. This work was financially supported by IAUPS.

\section{References}

Bailey HD, Armstrong BK, de Klerk NH, et al (2010). Exposure to diagnostic radiological procedures and the risk of childhood acute lymphoblastic leukemia. Cancer Epidemiol Biomarkers Prev, 19, 2897-909.

Bailey HD, Fritschi L, Metayer C et al., (2014). Parental occupational paint exposure and risk of childhood leukemia in the offspring: findings from the Childhood Leukemia International Consortium. Cancer Causes Control, 25, 1351-67.

Bailey HD, Fritschi L, Infante-Rivard C, et al (2014). Parental occupational pesticide exposure and the risk of childhood leukemia in the offspring: findings from the childhood leukemia international consortium. Int J Cancer, 135, 2157-72.

Bailey HD, Miller M, Greenop KR et al., (2014). Paternal intake of folate and vitamins B6 and B12 before conception and risk of childhood acute lymphoblastic leukemia. Cancer Causes Control, 25, 1615-25.

D'Angelo C, Costantini E, Kamal MA et al., (2015). Experimental model for ELF-EMF exposure: Concern for human health. Saudi J Biol Sci, 22, 75-84.

Deziel NC, Rull RP, Colt JS, et al (2014). Polycyclic aromatic hydrocarbons in residential dust and risk of childhood acute lymphoblastic leukemia. Environ Res, 133, 388-95.

Hashemizadeh H, Boroumand H, Noori R, et al (2013). Socioeconomic status and other characteristics in childhood leukemia. Iran J Ped Hematol Oncol, 3, 182-6.

Hauri D, Spycher B, Huss A, et al (2013). Domestic radon exposure and risk of childhood cancer: a prospective censusbased cohort study. Environ Health Perspect, 12, 1239-44.

Janghorbani M, Piraei E (2013). Association between air pollution and preterm birth among neonates born in Isfahan, Iran. J Res Med Sci, 18, 875-81.

Lupo PJ, Dietz DJ, Kamdar KY, et al (2014). Gene-environment interactions and the risk of childhood acute lymphoblastic leukemia: exploring the role of maternal folate genes and folic Acid fortification. Pediatr Hematol Oncol, 31, 160-8.

Marshall GM, Carter DR, Cheung BB, et al (2014). The prenatal origins of cancer. Nat Rev Cancer, 14, 277-89.

Metayer C, Milne E, Dockerty JD, (2014). Maternal supplementation with folic acid and other vitamins and risk of leukemia in offspring: a childhood leukemia international consortium study. Epidemiology, 25, 811-22.

Milne E, Greenop KR, Scott RJ et al., (2015). Folate pathway gene polymorphisms, maternal folic Acid use, and risk of childhood acute lymphoblastic leukemia. Cancer Epidemiol Biomarkers Prev, 24, 48-56.

Mohajer R, Salehi MH, Mohammadi J, et al (2013). The status of lead and cadmium in soils of high prevalenct gastrointestinal cancer region of Isfahan. J Res Med Sci, 18, 210-4.

Njoku K, Basta N, Mann KD et al., (2013). Socioeconomic variation in survival from childhood leukaemia in northern England, 1968-2010. Br J Cancer, 108, 2239-45.

Rajabli N, Naeimi-Tabeie M, Jahangirrad A, et al (2013). Epidemiology of leukemia and multiple myeloma in Golestan, Iran. Asian Pac J Cancer Prev, 14, 2233-6.

Rashidi M, Ramesht MH, Zohary M, et al (2013). Relation of air pollution with epidemiology of respiratory diseases in isfahan, Iran from 2005 to 2009. J Res Med Sci, 18, 1074-9.

Reisi N AA (2009). The metabolic syndrome in survivors of childhood acute lymphoblastic leukemia in Isfahan, Iran. $J$ Res Med Sci, 14, 111-6.

Reisi N, Azhir A, Hashemipour M, et al (2014). A diversity of cancer incidence and mortality in west asian populations. Ann Glob Health, 80, 346-357.

Sohrabi MR, Tarjoman T, Abadi A, et al (2010). Living near overhead high voltage transmission power lines as a risk factor for childhood acute lymphoblastic leukemia: a casecontrol study. Asian Pac J Cancer Prev, 11, 423-7.

Shi R, Gao Y, Zhang Y et al., (2013). Relationship between parental exposure to chemicals and risk of childhood acute leukemia. Zhonghua Lao Dong Wei Sheng Zhi Ye Bing Za Zhi, 31, 413-7.

Tahmasby B, Marnani AB, Maleki M, et al (2013). Blood malignancies in Mazandaran province of Iran. Asian Pac J Cancer Prev, 14, 1053-6.

Zierhut H, Linet MS, Robison LL, et al (2012). Family history of cancer and non-malignant diseases and risk of childhood acute lymphoblastic leukemia: a children's oncology group study. Cancer Epidemiol, 36, 45-51. 